\title{
Fungal Vaccines and Immunotherapeutics: Current Concepts and Future Challenges
}

\author{
Agostinho Carvalho ${ }^{1,2}$ - Cláudio Duarte-Oliveira ${ }^{1,2}$ - Samuel M. Gonçalves ${ }^{1,2}$. \\ António Campos Jr. ${ }^{3}$ João F. Lacerda ${ }^{4,5}$ - Cristina Cunha ${ }^{1,2}$
}

Published online: 7 March 2017

(C) Springer Science+Business Media New York 2017

\begin{abstract}
Purpose of review The remarkable advances in modern medicine have paradoxically resulted in a rapidly expanding population of immunocompromised patients displaying extreme susceptibility to life-threatening fungal infections. There are currently no licensed vaccines, and the prophylaxis and therapy of fungal infections in at-risk individuals remains challenging, contributing to undesirable mortality and morbidity rates. The design of successful antifungal preventive approaches has been hampered by an insufficient understanding of the dynamics of the host-fungus interaction and the mechanisms that underlie heterogenous immune responses to vaccines and immunotherapy.

Recent findings Recent advances in proteomics and glycomics have contributed to the identification of candidate antigens for use in subunit vaccines, novel adjuvants, and delivery systems to boost the efficacy of protective
\end{abstract}

This article is part of the Topical Collection on Pediatric Fungal Infection

Cristina Cunha

cristinacunha@med.uminho.pt

1 Life and Health Sciences Research Institute (ICVS), School of Medicine, University of Minho, Campus de Gualtar, 4710-057 Braga, Portugal

2 ICVS/3B's-PT Government Associate Laboratory, Braga/Guimarães, Portugal

3 Serviço de Transplantação de Medula Óssea (STMO), Instituto Português de Oncologia do Porto, Porto, Portugal

4 Instituto de Medicina Molecular, Faculdade de Medicina de Lisboa, Lisboa, Portugal

5 Serviço de Hematologia e Transplantação de Medula, Hospital de Santa Maria, Lisboa, Portugal vaccination responses that are becoming available, and several targets are being exploited in immunotherapeutic approaches. Summary We review some of the emerging concepts as well as the inherent challenges to the development of fungal vaccines and immunotherapies to protect at-risk individuals.

Keywords Fungal disease - Vaccination $\cdot$ Aspergillus · Candida $\cdot$ Immunotherapy $\cdot$ Personalized medicine

\section{Introduction}

In the last decades, the number of immunocompromised patients has increased, mostly due to advances in medical care, long-term hospitalization, and prophylactic treatments in patients at-risk, as well as due to acquired (e.g., HIV infection) or treatment-induced immunodeficiency in patients receiving hematopoietic stem-cell or solid organ transplants, or undergoing anticancer therapy [1-3]. Because of the complex underlying immune dysfunction, these patients are not able to efficiently eliminate opportunistic and otherwise commensal fungi, and are extremely susceptible to severe infections, ranging from superficial mucocutaneous disease to invasive deep-seated infections [4].

Currently available antifungal drugs have been proved efficient in in vitro and animal models of fungal disease; however, intrinsic activity against specific fungi is often lacking, and for those with anti-mold activity, resistance has become a worldwide concern [5•]. In addition, there are significant limitations in the sensitivity of diagnostic tests, which can delay the administration of proper antifungal therapy and lead to fatal outcomes [6]. While the troublesome mortality and morbidity rates have prompted efforts towards the development of new drugs and diagnostics, they have also encouraged research into vaccines to protect patients at-risk and to treat those with overt disease. Here, we review some of the 
emerging concepts in fungal vaccine and immunotherapy development, provide examples of promising approaches, and define the main challenges in delivering them to specific target populations.

\section{Activation of Antifungal Immunity}

The skin and the mucosal epithelial surfaces at body sites constantly exposed to environmental microorganisms provide the first line of innate resistance against fungal infection [7]. Epithelial cells are pivotal in discriminating commensal and pathogenic fungal morphotypes and act as an active extension of the innate immune system, operating as a surveillance mechanism sensing fungi and prompting antifungal effector responses [8,9]. Innate immune cells, including macrophages and dendritic cells (DCs), express a vast repertoire of pattern recognition receptors (PRRs) able to sense pathogenassociated molecular patterns and activate effector programs such as phagocytosis and production of oxygen radicals [10••]. In addition, specific molecules from the innate immune system such as collectins, ficolins, pentraxins, and complement components play a critical role in assisting fungal sensing by acting as opsonins and facilitating the interaction of phagocytes with fungi [11].

The activation of different profiles of adaptive immunity with both protective and non-protective functions against fungal pathogens is only possible due to the multiple sensing mechanisms existing in the innate arm of antifungal immunity (Fig. 1). Antigen-presenting cells such as DCs are responsible for sampling antigenic material in the environment and priming T cells via presentation of antigens on major histocompatibility complex class II or class I molecules, leading to the differentiation of $\mathrm{CD}^{+}$or $\mathrm{CD}^{+} \mathrm{T}$ cells, respectively [12]. Based on the expression pattern of lineage-specific transcription factors and production of cytokines after priming of naïve $\mathrm{CD}^{+} \mathrm{T}$ cells, the response is typically defined as $\mathrm{T}$ helper (Th)1, Th2, Th17, or T regulatory (Treg). Priming of naïve $\mathrm{CD}^{+} \mathrm{T}$ cells instead leads to differentiation of cytotoxic $\mathrm{T}$ (Tc) cells. The key ability of DCs to decode fungal antigens and translate them into qualitatively assorted adaptive $T$ cell immune responses positions them as logical cellular targets for the development of fungal vaccination strategies [13, 14].

Generation of diverse $\mathrm{T}$ cell immune responses is a crucial hallmark of adaptive antifungal immunity. Specifically, Th1 responses driven by IL-12 are required for the expression of protective immunity to fungi and are regarded as central for the design of effective fungal vaccines [15]. Induction of Th1 cells is required for the optimal activation of phagocytes at sites of infection, through the release of interferon (IFN)- $\gamma$ and by supporting the production of opsonizing antibodies. Th1 cell-based cross-protection has been accomplished with a universal immunogenic epitope from the cell wall of
Aspergillus fumigatus [16]. Because these protective Th1 cells cross-react with different fungi, and can be rapidly and efficiently immunoselected, the exciting possibility of adoptive fungus-specific $\mathrm{T}$ cell transfer for prophylaxis or treatment of patients at-risk is proposed [17•]. Another step forward towards a pan-fungal vaccine was recently provided by the identification of a widely conserved $\mathrm{CD}^{+} \mathrm{T}$ cell fungal epitope that binds a peptide derived from fungal calnexin [18•]. Calnexin, primarily known for its chaperone function in mammalian cells, is displayed on the cell surface of many fungi, and its inclusion in vaccine formulations was shown to induce resistance against multiple fungal pathogens, remarkably Blastomyces dermatitidis and Coccidioides posadasii, in murine models of vaccine immunity. It is also noteworthy that human pathogen- and vaccine-specific Th1, Th17, and Th2 memory cells display different frequencies but comparable diversity, and comprise not only clones polarized towards a single fate but also clones whose progeny has acquired multiple fates [19]. These findings unravel an unexpected degree of interclonal and intraclonal functional heterogeneity of the human $\mathrm{T}$ cell response and suggest that polarized responses resulting from the preferential expansion rather than priming are a factor to be considered in vaccine design.

In addition to Th1, Th17 cells play a key role in antifungal immunity, a concept supported by several clinical studies reporting Mendelian susceptibility to fungal infections of individuals with inborn errors of dectin-1, caspase recruitment domain-containing protein 9 (CARD9), signal transducer and activator of transcription (STAT)1, STAT3, and specifically, IL-17 immunity [20-23]. In experimental fungal infections, however, IL-17-dependent immunity has been reported to display both essential and dispensable roles [24], a finding pointing to a critical requirement of this pathway on specific stages and sites of infection, and to depend on the pathogen involved. In addition, Th17 cells are present in the fungusspecific $\mathrm{T}$ cell memory repertoire in humans $[25,26]$ and arbitrate some [27], but not all [28] vaccine-induced protection in mice, a finding highlighting an important regulatory function of the Th17 pathway on multiple adaptive immunity pathways. Different fungal morphotypes were recently found to induce distinct adaptive immune responses, with Th17 cell responses providing protection against cutaneous infection, while Th1 cell responses provided protection against systemic infection [29]. Altogether, these findings provide novel insights into the compartmentalization of antifungal Th cell responses and have critical implications for vaccine development strategies.

\section{Challenges and Opportunities in Fungal Vaccination}

Despite several efforts in the last years to produce a safe and effective vaccine against fungal disease, no significant 


\section{Correlates of protection}

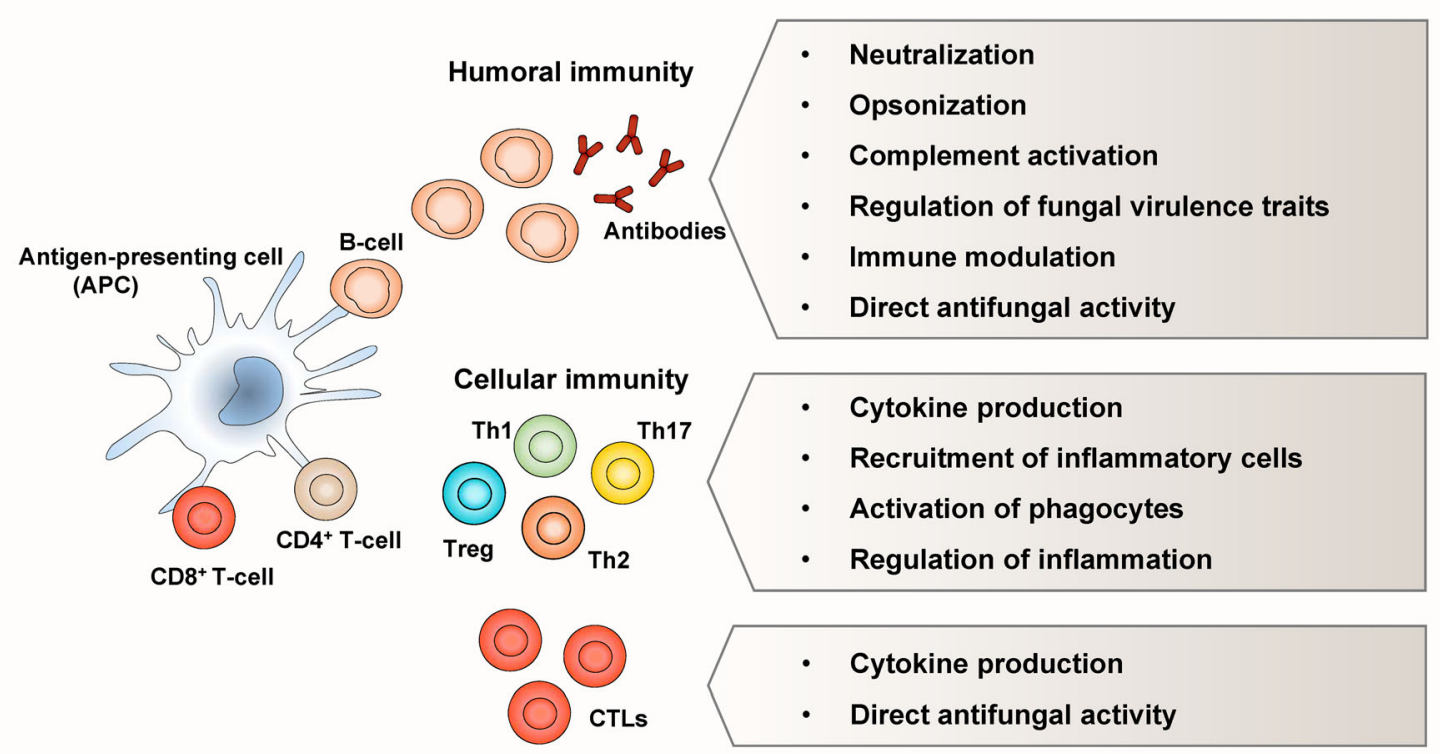

Fig. 1 Cellular and humoral immunity to fungi. Shown are the different correlates of protection elicited either by B cells and secreted antibodies (humoral immunity) or through the activity of T helper and cytotoxic T cells (cell-mediated immunity)

progress has been witnessed [30]. Because of the burden posed by fungal infections on worldwide healthcare systems, clinicians, researchers, and representatives of the pharmaceutical industry have strengthened their efforts on the development of antifungal vaccines. In recent years, several vaccine candidates have been reported, refined, and tested in animal models for their safety, immunogenicity, and efficacy, and at least two of them are now under study in human clinical trials [31]. A list with the major fungal vaccine candidates is shown in Table 1.

There are clinical settings in which the need for antifungal vaccines is more pronounced, namely those consisting of immunocompromised or debilitated hosts. Individuals with hematological malignancies and cancer, and that need to be subjected to transplant and/or immunosuppressive anticancer therapy immediately after diagnosis are highly susceptible to develop aggressive fungal infections such as invasive aspergillosis or deep-seated candidiasis. Unfortunately, there are some considerable obstacles that delay the implementation of vaccination strategies in these patients. Although claims that residual effective immune responses could effectively deal with the pathogen even after removal or loss of major groups of cells with antifungal effector ability $[52,53]$, the question remains as to whether a long-term protection could be obtained in these subjects, taking into account their underlying immune defect. One potential solution to ensure that molecular mechanisms involved in regulating vaccinerelated immune responses do not breakdown after immunization would be the use of novel vaccine formulations containing potent adjuvants aimed at eliciting protective responses [54].
Individuals with no obvious immune deficits, but that are placed at risk of life-threatening as the result of specific medical interventions, could benefit from these approaches. For example, patients who are certain to be immunosuppressed in the future, such as those in stem-cell transplant waiting lists, could be vaccinated prior to treatment while their immune response is intact [55•]. However, vaccine development for this group poses a problem of leaving too narrow a window before starting treatment to consider vaccination and/or initiate an appropriate schedule of vaccination. Another group of patients that could benefit from fungal vaccination include patients with breaches in their cutaneous or mucosal defenses, bearing permanent central venous catheters, or undergoing long-term hospitalization in intensive care units. Because of the possible side effects associated to the use of these approaches in this setting of patients, vaccine design should consider the nature of the relationship between opportunistic fungi and their human hosts [56]. For example, vaccination against commensals may disrupt the asymptomatic and possibly beneficial relationship between the fungus and its host. In the case of fungal pathogens with the ability to establish latency or to cause chronic or recurrent infections, vaccination may pose the risk of reactivating the target pathogen. Finally, vaccination-related exacerbations of allergic responses may arise when vaccinating against molds causing allergic disease. In this case, a successful vaccine strategy could be to dampen or redirect the nature of the immune response such as by shifting the bias from Th2 to Th1 responses.

Another important challenge to vaccine development is the testing of candidates in mice. While the human and murine immune systems might be regarded as quite similar, most 
Table 1 Major vaccine candidates against Aspergillus and Candida species

\begin{tabular}{lllll}
\hline Target pathogen(s) & Vaccine candidate(s) & Antigen & Mechanism(s) of protection & Reference(s) \\
\hline Aspergillus & Asp f16, Asp f3, Pep1, Gel1, glucans & Recombinant/subunit & Th1 & [26, 32, 33] \\
Aspergillus, Candida & Crf1 & Recombinant & Th1 & [16] \\
Aspergillus, Candida & Heat-killed Saccharomyces cerevisiae & Heat-killed whole & Th1, Th2, Th17 \\
Aspergillus & Particulate $\beta$-glucans & Subunit & Th1, Th17 \\
Candida & Als1, Als3, rAls3p-N (NDV-3) & Recombinant/subunit & Th1, Th17, antibodies \\
Candida & Fba peptide & Subunit & Antibodies \\
Candida & Met6 peptide & Subunit & Antibodies \\
Candida & Hyr1 & Recombinant/subunit & Antibodies \\
Candida & Live attenuated & Whole & T cells, antibodies \\
Candida & Mannan & Recombinant/subunit & Th1, antibodies \\
Candida & Eno1 & Recombinant & Antibodies \\
Candida & Sap2p PEV-7 ${ }^{\text {a }}$ & Recombinant truncated & Antibodies & {$[38]$} \\
Candida & Laminarin & Subunit & Antibodies & {$[40]$} \\
Candida & Cell wall surface proteins & Subunit & Antibodies, Th17 \\
\hline
\end{tabular}

${ }^{a}$ rAls3p-N (NDV-3) and Sap2p PEV-7 are under study in human clinical trials

studies have used inbred mice that lack the genetic diversity of "outbred" humans. Perhaps more importantly, laboratory mice do not have a natural exposure to certain airborne fungi (e.g., Aspergillus spp.), which contrasts with humans, who are repeatedly exposed to them during their lifetime. One possible solution for this caveat would be the use of humanized mouse models, modeling natural exposure conditions by continuous challenge, and conducting in vitro human testing.

\section{Decoding Antifungal Immunity into Vaccination Approaches}

Given the array of fungal motifs present at the cell surface, as well as those that become available to immune sensing upon digestion of the fungus by phagocytic cells, it is obvious that vaccine-induced protection to attenuated strains occurs through distinct innate immune receptors and downstream signaling adapters. In fact, significant changes in the expression of innate immune receptors during naïve-to-effector-to-memory transition have been revealed as one major early molecular signature upon vaccination [57]. The innate arm of the immune system is generally viewed as non-specific and unable to confer memory. Recently however, it has become clear that the innate immune response not only confers immunity, but can be trained prior to exposure to deliver immunological memory [58], a paradigm that was previously only attributed to the adaptive immune system. Monocytes and macrophages are among the main cells of the innate immune arm that can be trained using fungal $\beta$-glucan and dectin-1-mediated signaling via epigenetic reprogramming, particularly through histone trimethylation at H3K4 [59]. These epigenetic changes lead to cellular activation, enhanced cytokine production, and a change in the metabolic state of the cell with a shift from oxidative phosphorylation to aerobic glycolysis [59, $60,61 \bullet \cdot$. By endorsing a prolonged enhanced functional state in monocytes and macrophages after adequate priming, induction of trained immunity may be regarded as a promising new avenue for the design of fungal vaccines [62].

\section{Active Immunotherapy}

Fungal vaccines can be synonym of active immunotherapies as they promote immune responses with the goal of challenging and attacking fungal pathogens based on one or more specific antigens [63]. A growing number of approaches have been developed to identify proteins able to induce an antibody response or that represent targets of $\mathrm{T}$ cell immunity in patients with allergy or fungal infection [64]. Most of the fungal vaccines elicit antibody responses and their efficacy can be estimated through titer thresholds which may serve as vaccine surrogate markers even when the mechanism of protection is cellmediated [15]. Of note, the fungal vaccine under clinical trial for vulvovaginal candidiasis relies on recombinant secreted aspartic proteinase 2 proteins that induce protection through elicitation of neutralizing antibodies at the vaginal mucosa [47].

Regarding activation of $\mathrm{T}$ cell responses, acquisition of vaccine immunity to live attenuated strains of several dimorphic fungi was found to require induction of Th17 cells [27]. In contrast, protection to A. fumigatus relied on the differentiation of Th1 cells [28, 65]. Because these responses required different innate sensing pathways to be activated, these findings point to a crucial requirement of adjuvants in promoting $\mathrm{T}$ cell differentiation along specific effector pathways [54]. In this regard, Th1mediated protection has been reported across nearly all clinically relevant fungal diseases (Table 1). For example, among the most important fungal vaccine candidates leading to induction of 
strong Th1 responses are crude antigen preparations from A. fumigatus or recombinant fungal antigens alone [66-68] or in conjunction with $\mathrm{CpG}$ oligonucleotides as adjuvants $[16,32$, 69, 70] and the recombinant Als3p-N protein of Candida albicans formulated with alum adjuvant (designated as NDV-3 and currently under clinical trial) [37]. On the other hand, fungi have evolved their own complex mechanisms to subvert activation of effector T cell responses. For example, mucosal vaccination was found to prevent $\mathrm{T}$ cell priming by impairing chemokine signals on egress of inflammatory monocytes from the bone marrow and their recruitment to the lung [71]. Bearing in mind that inflammatory monocytes are pivotal in orchestrating pulmonary antifungal immunity by regulating neutrophil conidiocidal activity and their own differentiation to DCs, the fact that fungi can also modulate monocytes activity to prevent $\mathrm{T}$ cell activation is even more significant in terms of vaccine design [72].

The recent role proposed for metabolism [73••] and bioenergetics [74] in harnessing T cell memory and promoting rapid recall rates opened up new perspectives on how epigenetic and environmental mechanisms modulate memory differentiation and quality, thus opening new avenues for vaccine development. Additionally, subsets of T cells previously unanticipated to be involved in immune memory may also become important targets for new vaccines. One such example regards the invariant natural killer $\mathrm{T}$ cells that activate antifungal responses and promote airway hyperreactivity through the recognition of $\beta$-glucan [75] and the glycosphingolipid asperamide B [76]. Altogether, the currently available information suggests that the development of a multivalent vaccine inducing an immune response against multiple, unrelated fungal virulence traits may be the best approach towards the first antifungal vaccine approved for human use [31].

\section{Passive Immunotherapy}

Passive immunotherapy strategies comprise laboratorysynthesized antibodies or other immune system components that can be administered to patients and do not stimulate the immune system nor "actively" respond to infection in the way a vaccine does [77]. In this regard, a number of monoclonal human recombinant antibodies and their fragments have already been tested in experimental fungal diseases [78]. Another example of passive immunotherapy regards the long pentraxin 3 (PTX3), a soluble PRR which has been found to play a pivotal role in the establishment of adequate protection against invasive aspergillosis in allogeneic stem-cell transplant recipients [79••]. Remarkably, PTX3 alone [80] or in combination with antifungals [81] was shown to confer protection in animal models of invasive aspergillosis, therefore highlighting the potential of this molecule as an immunotherapeutic target in high-risk patients. In addition, the potential usefulness of PRR agonists to treat fungal infections was also recently addressed in a clinical trial assessing the efficacy of topical applications of imiquimod (a Toll-like receptor 7 (TLR7) ligand) to treat patients afflicted with the chronic infection chromoblastomycosis $[82 \cdot]$.

\section{Fungal Vaccination in the Era of Personalized Medicine}

The decoding of the complexity in the immune response to vaccines demands for an integrative network comprising advanced immunology approaches, systems biology, and immunogenetics, in the areas of pathogen and host biology and their interaction. Vaccinomics is a term that was recently coined to describe the field of immunogenomics applied to the elucidation of mechanisms accountable for interindividual immune responses to vaccines [83]. The genetic variability of the immune system is nowadays recognized as one major determinant of the quality of the antifungal immune response, particularly in the relative absence of immune redundancy observed in immunocompromised individuals [84, 85]. Therefore, genetic profiling of immune responses is nowadays regarded as a promising approach to exploit in the future towards improved diagnosis and therapy of fungal diseases [86•]. More specifically, functional polymorphisms in certain immune genes, including that coding for IFN- $\gamma$ [87], have been found to underlie variable immune responses to a given vaccine. Along the same line, the qualitative analysis of A. fumigatus-specific immune responses in hematological patients has been proposed as a promising immunodiagnostic approach [88•]. Thus, by interpreting immunogenetic signatures and identifying even subtle differences in immune profiles, it may be possible to discriminate response efficiencies to antifungal vaccines. The finding that the genetically determined deficiency of TLR 3 compromises the ability of DCs to activate protective memory $\mathrm{CD}^{+} \mathrm{T}$ cells, thereby predisposing to invasive aspergillosis among hematopoietic stem-cell transplant recipients, is one such example [65].

Given the complexity of innate and adaptive antifungal immune responses, data from functional genomics, transcriptomics, proteomics, and metabolomics will probably be required to provide the best performance in predicting vaccine efficacy [89]. Within these examples, host microbiomics is of particular interest due to their protective function against colonization by endogenous and exogenous microorganisms and even in the modulation of host immune responses [90]. For example, catabolites originating from the breakdown of tryptophan by intestinal microbiota were found to activate the aryl hydrocarbon receptor and fine-tune mucosal reactivity to C. albicans [91], and dectin-1-mediated signaling was required to maintain intestinal immune homeostasis [92]. Whether the endogenous lung microbiota also plays a role in 
susceptibility to and progression of fungal diseases is currently a hot topic of research [93]. Altogether, the comprehensive information about the biology of the host-fungus interaction and the intrinsic and extrinsic factors likely influencing the development of disease could be used in the rational and personalized development of new vaccine candidates.

\section{Concluding Remarks}

Vaccination is unquestionably one of the major public health successes in the history of medicine. However, since the first safe and efficacious vaccine has eradicated smallpox, and after more than a dozen lethal bacterial and viral infections have been kept at bay by vaccination, effective fungal vaccines for clinical use are not available. We have witnessed exciting recent developments in our understanding of the complex molecular and cellular pathways through which the immune system controls fungi and responds to infection. The combination of multidisciplinary approaches based on whole-genome and "omics" techniques, advanced bioinformatics, and systems biology may further contribute to the identification of novel immunogenic antigens and cellular pathways amenable to manipulation, as well as novel adjuvants and delivery systems. Ultimately, this new conceptual framework in vaccine discovery and design may lay the foundation for the first successful fungal vaccines.

Acknowledgments This work was supported by the Northern Portugal Regional Operational Programme (NORTE 2020), under the Portugal 2020 Partnership Agreement, through the European Regional Development Fund (FEDER) (NORTE-01-0145-FEDER-000013), and the Fundação para a Ciência e Tecnologia (FCT) (contracts IF/00735/ 2014 to A.C., and SFRH/BPD/96176/2013 to C.C).

\section{Compliance with Ethical Standards}

Conflict of Interest Agostinho Carvalho, Cláudio Duarte-Oliveira, Samuel M. Gonçalves, António Campos Jr., João F. Lacerda and Cristina Cunha declare that they have no conflict of interest.

Human and Animal Rights and Informed Consent This article does not contain any studies with human or animal subjects performed by any of the authors.

\section{References}

Papers of particular interest, published recently, have been highlighted as:

- Of importance

•. Of major importance

1. Kontoyiannis DP, Marr KA, Park BJ, Alexander BD, Anaissie EJ, Walsh TJ, et al. Prospective surveillance for invasive fungal infections in hematopoietic stem cell transplant recipients, 2001-2006: overview of the Transplant-Associated Infection Surveillance
Network (TRANSNET) Database. Clin Infect Dis. 2010;50(8): 1091-100. doi:10.1086/651263.

2. Pagano L, Caira M, Candoni A, Offidani M, Martino B, Specchia $\mathrm{G}$, et al. Invasive aspergillosis in patients with acute myeloid leukemia: a SEIFEM-2008 registry study. Haematologica. 2010;95(4): 644-50. doi:10.3324/haematol.2009.012054.

3. Pappas PG, Alexander BD, Andes DR, Hadley S, Kauffman CA, Freifeld A, et al. Invasive fungal infections among organ transplant recipients: results of the Transplant-Associated Infection Surveillance Network (TRANSNET). Clin Infect Dis. 2010;50(8): 1101-11. doi:10.1086/651262.

4. Brown GD, Denning DW, Gow NA, Levitz SM, Netea MG, White TC. Hidden killers: human fungal infections. Sci Transl Med. 2012;4(165):165rv13. doi:10.1126/scitranslmed.3004404.

5. Verweij PE, Chowdhary A, Melchers WJ, Meis JF. Azole resistance in Aspergillus fumigatus: can we retain the clinical use of moldactive antifungal azoles? Clin Infect Dis. 2016;62(3):362-8. doi:10. $1093 / \mathrm{cid} / \mathrm{civ} 885$. A complete overview on azole resistance in Aspergillus fumigatus and its global health consequences.

6. Kozel TR, Wickes B. Fungal diagnostics. Cold Spring Harbor Perspect Med. 2014;4(4):a019299. doi:10.1101/cshperspect. a019299.

7. Carvalho A, Cunha C, Iannitti RG, Casagrande A, Bistoni F, Aversa F, et al. Host defense pathways against fungi: the basis for vaccines and immunotherapy. Front Microbiol. 2012;3:176. doi:10.3389/ fmicb.2012.00176.

8. Duhring S, Germerodt S, Skerka C, Zipfel PF, Dandekar T, Schuster S. Host-pathogen interactions between the human innate immune system and Candida albicans - understanding and modeling defense and evasion strategies. Front Microbiol. 2015;6:625. doi:10.3389/fmicb.2015.00625.

9. Osherov N. Interaction of the pathogenic mold Aspergillus fumigatus with lung epithelial cells. Front Microbiol. 2012;3:346. doi:10.3389/fmicb.2012.00346.

10.• Erwig LP, Gow NA. Interactions of fungal pathogens with phagocytes. Nat Rev Microbiol. 2016;14(3):163-76. doi:10.1038/ nrmicro.2015.21. A comprehensive review of the mechanisms involved in the interaction between fungal pathogens and phagocytes.

11. Jaillon S, Ponzetta A, Magrini E, Barajon I, Barbagallo M, Garlanda $\mathrm{C}$, et al. Fluid phase recognition molecules in neutrophil-dependent immune responses. Semin Immunol. 2016;28(2):109-18. doi:10.1016/j.smim.2016.03.005.

12. Steinman RM. Decisions about dendritic cells: past, present, and future. Annu Rev Immunol. 2012;30:1-22. doi:10.1146/annurevimmunol-100311-102839.

13. Roy RM, Klein BS. Dendritic cells in antifungal immunity and vaccine design. Cell Host Microbe. 2012;11(5):436-46. doi:10. 1016/j.chom.2012.04.005.

14. Steinman RM. Dendritic cells in vivo: a key target for a new vaccine science. Immunity. 2008;29(3):319-24. doi:10.1016/j.immuni. 2008.08.001.

15. Spellberg B, Ibrahim AS, Lin L, Avanesian V, Fu Y, Lipke P, et al. Antibody titer threshold predicts anti-candidal vaccine efficacy even though the mechanism of protection is induction of cellmediated immunity. J Infect Dis. 2008;197(7):967-71.

16. Stuehler C, Khanna N, Bozza S, Zelante T, Moretti S, Kruhm M, et al. Cross-protective TH1 immunity against Aspergillus fumigatus and Candida albicans. Blood. 2011;117(22):5881-91. doi:10. 1182/blood-2010-12-325084.

17. Stuehler C, Nowakowska J, Bernardini C, Topp MS, Battegay M, Passweg J, et al. Multispecific Aspergillus T cells selected by CD137 or CD154 induce protective immune responses against the most relevant mold infections. J Infect Dis. 2015;211(8): 1251-61. doi:10.1093/infdis/jiu607. A study describing a rapid 
protocol for the selection of fungus-specific T-cells suitable for adoptive transfer.

18. Wuthrich M, Brandhorst TT, Sullivan TD, Filutowicz H, Sterkel A, Stewart D, et al. Calnexin induces expansion of antigen-specific CD4(+) T cells that confer immunity to fungal ascomycetes via conserved epitopes. Cell Host Microbe. 2015;17(4):452-65. doi: 10.1016/j.chom.2015.02.009. First description of a broadspectrum fungal vaccine based on the chaperone calnexin.

19. Becattini S, Latorre D, Mele F, Foglierini M, De Gregorio C, Cassotta A, et al. T cell immunity. Functional heterogeneity of human memory CD4(+) T cell clones primed by pathogens or vaccines. Science. 2015;347(6220):400-6. doi:10.1126/science. 1260668

20. Ferwerda B, Ferwerda G, Plantinga TS, Willment JA, van Spriel $\mathrm{AB}$, Venselaar $\mathrm{H}$, et al. Human dectin-1 deficiency and mucocutaneous fungal infections. N Engl J Med. 2009;361(18):1760-7. doi: 10.1056/NEJMoa0901053.

21. Glocker EO, Hennigs A, Nabavi M, Schaffer AA, Woellner C, Salzer U, et al. A homozygous CARD9 mutation in a family with susceptibility to fungal infections. N Engl J Med. 2009;361(18): 1727-35. doi:10.1056/NEJMoa0810719.

22. Puel A, Cypowyj S, Bustamante J, Wright JF, Liu L, Lim HK, et al. Chronic mucocutaneous candidiasis in humans with inborn errors of interleukin-17 immunity. Science. 2011;332(6025):65-8. doi:10. 1126/science.1200439.

23. van de Veerdonk FL, Plantinga TS, Hoischen A, Smeekens SP, Joosten LA, Gilissen C, et al. STAT1 mutations in autosomal dominant chronic mucocutaneous candidiasis. N Engl J Med. 2011;365(1):54-61. doi:10.1056/NEJMoa1100102.

24. Conti HR, Gaffen SL. IL-17-mediated immunity to the opportunistic fungal pathogen Candida albicans. J Immunol. 2015;195(3): 780-8. doi:10.4049/jimmunol.1500909.

25. Acosta-Rodriguez EV, Rivino L, Geginat J, Jarrossay D, Gattorno M, Lanzavecchia A, et al. Surface phenotype and antigenic specificity of human interleukin 17-producing T helper memory cells. Nat Immunol. 2007;8(6):639-46.

26. Bozza S, Clavaud C, Giovannini G, Fontaine T, Beauvais A, Sarfati $\mathrm{J}$, et al. Immune sensing of Aspergillus fumigatus proteins, glycolipids, and polysaccharides and the impact on Th immunity and vaccination. J Immunol. 2009.

27. Wuthrich M, Gern B, Hung CY, Ersland K, Rocco N, Pick-Jacobs J, et al. Vaccine-induced protection against 3 systemic mycoses endemic to North America requires Th17 cells in mice. J Clin Invest. 2011;121(2):554-68. doi:10.1172/JCI43984.

28. De Luca A, Iannitti RG, Bozza S, Beau R, Casagrande A, D'Angelo C, et al. CD4(+) T cell vaccination overcomes defective cross-presentation of fungal antigens in a mouse model of chronic granulomatous disease. J Clin Invest. 2012;122(5):1816-31. doi: 10.1172/JCI60862.

29. Kashem SW, Igyarto BZ, Gerami-Nejad M, Kumamoto Y, Mohammed J, Jarrett E, et al. Candida albicans morphology and dendritic cell subsets determine $\mathrm{T}$ helper cell differentiation. Immunity. 2015;42(2):356-66. doi:10.1016/j.immuni.2015.01. 008.

30. Cassone A, Casadevall A. Recent progress in vaccines against fungal diseases. Curr Opin Microbiol. 2012;15(4):427-33. doi:10. 1016/j.mib.2012.04.004

31. Cassone A. Development of vaccines for Candida albicans: fighting a skilled transformer. Nat Rev Microbiol. 2013;11(12):884-91. doi:10.1038/Nrmicro3156.

32. Ito JI, Lyons JM, Hong TB, Tamae D, Liu YK, Wilczynski SP, et al. Vaccinations with recombinant variants of Aspergillus fumigatus allergen Asp f 3 protect mice against invasive aspergillosis. Infect Immun. 2006;74(9):5075-84. doi:10.1128/IAI.00815-06.

33. Bozza S, Gaziano R, Lipford GB, Montagnoli C, Bacci A, Di Francesco $\mathrm{P}$, et al. Vaccination of mice against invasive aspergillosis with recombinant Aspergillus proteins and $\mathrm{CpG}$ oligodeoxynucleotides as adjuvants. Microbes Infect/Inst Pasteur. 2002;4(13):1281-90.

34. Clemons KV, Martinez M, Chen V, Liu M, Yoon HJ, Stevens DA. Protection against experimental aspergillosis by heat-killed yeast is not antibody dependent. Med Mycol. 2014;52(4):422-6. doi:10. 1093/mmy/myt015.

35. Liu M, Clemons KV, Bigos M, Medovarska I, Brummer E, Stevens DA. Immune responses induced by heat killed Saccharomyces cerevisiae: a vaccine against fungal infection. Vaccine. 2011;29(9):1745-53. doi:10.1016/j.vaccine.2010.12.119.

36. Clemons KV, Danielson ME, Michel KS, Liu M, Ottoson NC, Leonardo SM, et al. Whole glucan particles as a vaccine against murine aspergillosis. J Med Microbiol. 2014;63(Pt 12):1750-9. doi:10.1099/jmm.0.079681-0.

37. Ibrahim AS, Luo G, Gebremariam T, Lee H, Schmidt CS, Hennessey Jr JP, et al. NDV-3 protects mice from vulvovaginal candidiasis through T- and B-cell immune response. Vaccine. 2013. doi:10.1016/j.vaccine.2013.09.016.

38. Lin L, Ibrahim AS, Xu X, Farber JM, Avanesian V, Baquir B, et al. Th1-Th17 cells mediate protective adaptive immunity against Staphylococcus aureus and Candida albicans infection in mice. PLoS Pathog. 2009;5(12), e1000703.

39. Cutler JE, Corti M, Lambert P, Ferris M, Xin H. Horizontal transmission of Candida albicans and evidence of a vaccine response in mice colonized with the fungus. PLoS One. 2011;6(7), e22030. doi: 10.1371/journal.pone.0022030.

40. Xin H. Active immunizations with peptide-DC vaccines and passive transfer with antibodies protect neutropenic mice against disseminated candidiasis. Vaccine. 2016;34(2):245-51. doi:10.1016/j. vaccine.2015.11.035.

41. Luo G, Ibrahim AS, French SW, Edwards Jr JE, Fu Y. Active and passive immunization with rHyrlp-N protects mice against hematogenously disseminated candidiasis. PLoS One. 2011;6(10), e25909. doi:10.1371/journal.pone.0025909.

42. Martinez-Lopez R, Nombela C, Diez-Orejas R, Monteoliva L, Gil C. Immunoproteomic analysis of the protective response obtained from vaccination with Candida albicans ecm 33 cell wall mutant in mice. Proteomics. 2008;8(13):2651-64. doi:10.1002/pmic. 200701056.

43. Saville SP, Lazzell AL, Chaturvedi AK, Monteagudo C, LopezRibot JL. Efficacy of a genetically engineered Candida albicans tet-NRG1 strain as an experimental live attenuated vaccine against hematogenously disseminated candidiasis. Clin Vac Immunol: CVI. 2009;16(3):430-2. doi:10.1128/CVI.00480-08.

44. Paulovicova E, Machova E, Tulinska J, Bystricky S. Cell and antibody mediated immunity induced by vaccination with novel Candida dubliniensis mannan immunogenic conjugate. Int Immunopharmacol. 2007;7(10):1325-33. doi:10.1016/j.intimp. 2007.05.014.

45. Xin H, Dziadek S, Bundle DR, Cutler JE. Synthetic glycopeptide vaccines combining beta-mannan and peptide epitopes induce protection against candidiasis. Proc Natl Acad Sci U S A. 2008;105(36):13526-31. doi:10.1073/pnas.0803195105.

46. Li W, Hu X, Zhang X, Ge Y, Zhao S, Hu Y, et al. Immunisation with the glycolytic enzyme enolase confers effective protection against Candida albicans infection in mice. Vaccine. 2011;29(33):552633. doi:10.1016/j.vaccine.2011.05.030.

47. Sandini S, La Valle R, Deaglio S, Malavasi F, Cassone A, De Bernardis F. A highly immunogenic recombinant and truncated protein of the secreted aspartic proteases family (rSap2t) of Candida albicans as a mucosal anticandidal vaccine. FEMS Immunol Med Microbiol. 2011;62(2):215-24. doi:10.1111/j.1574695X.2011.00802.x.

48. Bromuro C, Romano M, Chiani P, Berti F, Tontini M, Proietti D, et al. Beta-glucan-CRM197 conjugates as candidates antifungal 
vaccines. Vaccine. 2010;28(14):2615-23. doi:10.1016/j.vaccine. 2010.01.012.

49. Rachini A, Pietrella D, Lupo P, Torosantucci A, Chiani P, Bromuro C, et al. An anti-beta-glucan monoclonal antibody inhibits growth and capsule formation of Cryptococcus neoformans in vitro and exerts therapeutic, anticryptococcal activity in vivo. Infect Immun. 2007;75(11):5085-94. doi:10.1128/IAI.00278-07.

50. Torosantucci A, Bromuro C, Chiani P, De Bernardis F, Berti F, Galli $\mathrm{C}$, et al. A novel glyco-conjugate vaccine against fungal pathogens. J Exp Med. 2005;202(5):597-606. doi:10.1084/jem.20050749.

51. Carneiro C, Correia A, Lima T, Vilanova M, Pais C, Gomes AC, et al. Protective effect of antigen delivery using monoolein-based liposomes in experimental hematogenously disseminated candidiasis. Acta Biomater. 2016;39:133-45. doi:10.1016/j.actbio.2016.05. 001.

52. Koh AY, Kohler JR, Coggshall KT, Van Rooijen N, Pier GB. Mucosal damage and neutropenia are required for Candida albicans dissemination. PLoS Pathog. 2008;4(2), e35. doi:10. 1371/journal.ppat.0040035.

53. Wuthrich M, Filutowicz HI, Warner T, Deepe Jr GS, Klein BS. Vaccine immunity to pathogenic fungi overcomes the requirement for CD4 help in exogenous antigen presentation to CD8+ T cells: implications for vaccine development in immune-deficient hosts. J Exp Med. 2003;197(11):1405-16. doi:10.1084/jem.20030109.

54. Levitz SM, Golenbock DT. Beyond empiricism: informing vaccine development through innate immunity research. Cell. 2012;148(6): 1284-92. doi:10.1016/j.cell.2012.02.012.

55. Levitz SM. Aspergillus vaccines: hardly worth studying or worthy of hard study? Med Mycol. 2017;55(1):103-8. doi:10.1093/mmy/ myw081. An overview on the emerging concepts and future challenges associated with Aspergillus vaccination.

56. Hamad M. Universal fungal vaccines: could there be light at the end of the tunnel? Human Vac Immunotherapeutics. 2012;8(12):1758 63. doi:10.4161/hv.21838.

57. Pulendran B, Li S, Nakaya HI. Systems vaccinology. Immunity. 2010;33(4):516-29. doi:10.1016/j.immuni.2010.10.006.

58. Quintin J, Saeed S, Martens JH, Giamarellos-Bourboulis EJ, Ifrim DC, Logie C, et al. Candida albicans infection affords protection against reinfection via functional reprogramming of monocytes. Cell Host Microbe. 2012;12(2):223-32. doi:10.1016/j.chom.2012. 06.006 .

59. Saeed S, Quintin J, Kerstens HH, Rao NA, Aghajanirefah A, Matarese F, et al. Epigenetic programming of monocyte-tomacrophage differentiation and trained innate immunity. Science. 2014;345(6204):1251086. doi:10.1126/science.1251086.

60. Arts RJ, Novakovic B, Ter Horst R, Carvalho A, Bekkering S, Lachmandas E, et al. Glutaminolysis and fumarate accumulation integrate immunometabolic and epigenetic programs in trained immunity. Cell Metab. 2016. doi:10.1016/j.cmet.2016.10.008.

61.• Cheng SC, Quintin J, Cramer RA, Shepardson KM, Saeed S, Kumar V, et al. mTOR- and HIF-1alpha-mediated aerobic glycolysis as metabolic basis for trained immunity. Science. 2014;345(6204):1250684. doi:10.1126/science.1250684. A first study describing the metabolic pathways involved in the induction of innate immune memory.

62. van der Meer JW, Joosten LA, Riksen N, Netea MG. Trained immunity: a smart way to enhance innate immune defence. Mol Immunol. 2015;68(1):40-4. doi:10.1016/j.molimm.2015.06.019.

63. Carvalho A, Cunha C, Bistoni F, Romani L. Immunotherapy of aspergillosis. Clin Microbiol Infect: Off Publ Eur Soc Clin Microbiol Infect Dis. 2012;18(2):120-5. doi:10.1111/j.1469-0691. 2011.03681.x.

64. Kniemeyer O, Ebel F, Kruger T, Bacher P, Scheffold A, Luo T, et al. Immunoproteomics of Aspergillus for the development of biomarkers and immunotherapies. Proteomics Clin Appl. 2016;10(910):910-21. doi:10.1002/prca.201600053.
65. Carvalho A, De Luca A, Bozza S, Cunha C, D'Angelo C, Moretti S, et al. TLR3 essentially promotes protective class I-restricted memory CD8(+) T-cell responses to Aspergillus fumigatus in hematopoietic transplanted patients. Blood. 2012;119(4):967-77. doi:10. 1182/blood-2011-06-362582.

66. Champer J, Diaz-Arevalo D, Champer M, Hong TB, Wong M, Shannahoff M, et al. Protein targets for broad-spectrum mycosis vaccines: quantitative proteomic analysis of Aspergillus and Coccidioides and comparisons with other fungal pathogens. Ann N Y Acad Sci. 2012;1273:44-51. doi:10.1111/j.1749-6632.2012. 06761.x.

67. Diaz-Arevalo D, Bagramyan K, Hong TB, Ito JI, Kalkum M. CD4+ $\mathrm{T}$ cells mediate the protective effect of the recombinant Asp f3based anti-aspergillosis vaccine. Infect Immun. 2011;79(6):225766. doi:10.1128/IAI.01311-10.

68. Tramsen L, Schmidt S, Koehl U, Huenecke S, Latge JP, Roeger F, et al. No effect of antifungal compounds on functional properties of human antifungal T-helper type 1 cells. Transpl Infect Dis: Off J Transplant Soc. 2013;15(4):430-4. doi:10.1111/tid.12089.

69. Bozza S, Clavaud C, Giovannini G, Fontaine T, Beauvais A, Sarfati $\mathrm{J}$, et al. Immune sensing of Aspergillus fumigatus proteins, glycolipids, and polysaccharides and the impact on Th immunity and vaccination. J Immunol. 2009;183(4):2407-14. doi:10.4049/ jimmunol.0900961.

70. Cenci E, Mencacci A, Bacci A, Bistoni F, Kurup VP, Romani L. T cell vaccination in mice with invasive pulmonary aspergillosis. $\mathrm{J}$ Immunol. 2000;165(1):381-8.

71. Wuthrich M, Ersland K, Sullivan T, Galles K, Klein BS. Fungi subvert vaccine $\mathrm{T}$ cell priming at the respiratory mucosa by preventing chemokine-induced influx of inflammatory monocytes. Immunity. 2012;36(4):680-92. doi:10.1016/j.immuni.2012.02. 015 .

72. Espinosa V, Jhingran A, Dutta O, Kasahara S, Donnelly R, Du P, et al. Inflammatory monocytes orchestrate innate antifungal immunity in the lung. PLoS Pathog. 2014;10(2), e1003940. doi:10.1371/ journal.ppat.1003940.

73.• Chang CH, Pearce EL. Emerging concepts of T cell metabolism as a target of immunotherapy. Nat Immunol. 2016;17(4):364-8. doi:10. 1038/ni.3415. A critical review discussing the emerging concept of repurposing T-cell metabolism towards immunotherapy.

74. van der Windt GJ, O'Sullivan D, Everts B, Huang SC, Buck MD, Curtis JD, et al. CD8 memory T cells have a bioenergetic advantage that underlies their rapid recall ability. Proc Natl Acad Sci U S A. 2013;110(35):14336-41. doi:10.1073/pnas.1221740110.

75. Cohen NR, Tatituri RV, Rivera A, Watts GF, Kim EY, Chiba A, et al. Innate recognition of cell wall beta-glucans drives invariant natural killer $\mathrm{T}$ cell responses against fungi. Cell Host Microbe. 2011;10(5):437-50. doi:10.1016/j.chom.2011.09.011.

76. Albacker LA, Chaudhary V, Chang YJ, Kim HY, Chuang YT, Pichavant $\mathrm{M}$, et al. Invariant natural killer T cells recognize a fungal glycosphingolipid that can induce airway hyperreactivity. Nat Med. 2013;19(10):1297-304. doi:10.1038/nm.3321.

77. Lehrnbecher T, Kalkum M, Champer J, Tramsen L, Schmidt S, Klingebiel T. Immunotherapy in invasive fungal infection - focus on invasive aspergillosis. Curr Pharm Des. 2013;19(20):3689-712.

78. Casadevall A, Pirofski LA. Immunoglobulins in defense, pathogenesis, and therapy of fungal diseases. Cell Host Microbe. 2012;11(5): 447-56. doi:10.1016/j.chom.2012.04.004.

79.• Cunha C, Aversa F, Lacerda JF, Busca A, Kurzai O, Grube M, et al. Genetic PTX3 deficiency and aspergillosis in stem-cell transplantation. N Eng1 J Med. 2014;370(5):421-32. doi:10.1056/ NEJMoa1211161. A first study highlighting PTX3-based immunotherapy in the personalized management of invasive aspergillosis.

80. Lo Giudice P, Campo S, Verdoliva A, Rivieccio V, Borsini F, De Santis R, et al. Efficacy of PTX3 in a rat model of invasive 
aspergillosis. Antimicrob Agents Chemother. 2010;54(10):4513-5. doi:10.1128/AAC.00674-10.

81. Lo Giudice P, Campo S, De Santis R, Salvatori G. Effect of PTX3 and voriconazole combination in a rat model of invasive pulmonary aspergillosis. Antimicrob Agents Chemother. 2012;56(12):6400-2. doi:10.1128/AAC.01000-12.

82. Junior WB, Spina R, Lota PR, Valente NS, Brown GD, et al. Topical application of Imiquimod as a treatment for chromoblastomycosis. Clin Infect Dis: Of Publ Infect Dis Soc Am. 2014. doi:10.1093/cid/ciu168. A study describing the use of Toll-like receptor agonists to treat chronic fungal infections.

83. Poland GA, Oberg AL. Vaccinomics and bioinformatics: accelerants for the next golden age of vaccinology. Vaccine. 2010;28(20): 3509-10. doi:10.1016/j.vaccine.2010.03.031.

84. Cunha C, Aversa F, Romani L, Carvalho A. Human genetic susceptibility to invasive aspergillosis. PLoS Pathog. 2013;9(8), e1003434. doi:10.1371/journal.ppat.1003434.

85. Smeekens SP, van de Veerdonk FL, Kullberg BJ, Netea MG. Genetic susceptibility to Candida infections. EMBO Mol Med. 2013;5(6):805-13. doi:10.1002/emmm.201201678.

86. Oliveira-Coelho A, Rodrigues F, Campos Jr A, Lacerda JF, Carvalho A, Cunha C. Paving the way for predictive diagnostics and personalized treatment of invasive aspergillosis. Front Microbiol. 2015;6:411. doi:10.3389/fmicb.2015.00411. An overview of the genetics of susceptibility to invasive aspergillosis and its impact on diagnostics and treatment.

87. Ovsyannikova IG, Haralambieva IH, Kennedy RB, O'Byrne MM, Pankratz VS, Poland GA. Genetic variation in IL18R1 and IL18 genes and inteferon gamma ELISPOT response to smallpox vaccination: an unexpected relationship. J Infect Dis. 2013;208(9):1422-30. doi:10.1093/infdis/jit341.

88. Potenza L, Vallerini D, Barozzi P, Riva G, Forghieri F, Beauvais A, et al. Characterization of specific immune responses to different Aspergillus antigens during the course of invasive aspergillosis in hematologic patients. PLoS One. 2013;8(9):e74326. doi:10.1371/ journal.pone.0074326. A study describing the use of Aspergillusspecific $T$-cell responses in fungal immunodiagnostic approaches.

89. Kennedy RB, Poland GA. The top five "game changers" in vaccinology: toward rational and directed vaccine development. Omics: J Integrat Biol. 2011;15(9):533-7. doi:10.1089/omi.2011. 0012.

90. Kamada N, Seo SU, Chen GY, Nunez G. Role of the gut microbiota in immunity and inflammatory disease. Nat Rev Immunol. 2013;13(5):321-35. doi:10.1038/nri3430.

91. Zelante T, Iannitti RG, Cunha C, De Luca A, Giovannini G, Pieraccini G, et al. Tryptophan catabolites from microbiota engage aryl hydrocarbon receptor and balance mucosal reactivity via interleukin-22. Immunity. 2013;39(2):372-85. doi:10.1016/j.immuni. 2013.08.003.

92. Iliev ID, Funari VA, Taylor KD, Nguyen Q, Reyes CN, Strom SP, et al. Interactions between commensal fungi and the C-type lectin receptor Dectin-1 influence colitis. Science. 2012;336(6086):1314 7. doi:10.1126/science. 1221789.

93. Goncalves SM, Lagrou K, Duarte-Oliveira C, Maertens JA, Cunha $\mathrm{C}$, Carvalho A. The microbiome-metabolome crosstalk in the pathogenesis of respiratory fungal diseases. Virulence. 2016:1-12. doi: 10.1080/21505594.2016.1257458. 